\title{
What drives utilization of primary care facilities?: evidence from a national
}

\section{facility survey}

\author{
Lan $\mathrm{TH} \mathrm{Vu}^{1}$, Sarah Bales ${ }^{1}$, Caryn Bredenkamp ${ }^{2}$, \\ ${ }^{1}$ Hanoi University of Public Health \\ ${ }^{2}$ World Bank Vietnam
}

Correspondence details: Lan TH Vu, Hanoi University of Public Health, ${ }^{\text {st }}$ Duc Thang, Bac

Tu Liem, Hanoi, Vietnam, Phone: (84)-918358886, email: Vhl@huph.edu.vn

\section{Author's information}

- Lan TH Vu, MD, PhD, Hanoi University of Public Health

- Sarah Bales, PhD, Hanoi University of Public Health

- Caryn Bredenkamp, PhD, World Bank Vietnam 


\title{
What drives utilization of primary care facilities?: evidence from a national facility survey
}

\begin{abstract}
This analysis aims to assess the association between commune health station (CHS) service availability/readiness and health service utilization. Data from the 2015 Vietnam District and Commune Health Facility Survey was used to build a series of multivariate negative binomial regressions to measure the association between domains of service availability/readiness and CHS's average number of visits per capita. Three domains of service availability/readiness are significantly associated with higher utilization rates: health infrastructure, basic equipment availability, and capacity to deliver services for noncommunicable diseases. If all three modifiable CHS characteristics were to be improved from their current level, the predicted utilization rate of the CHS would be 3.3 to 3.7 times as high as current levels. Investments in improving facility infrastructure, making available essential equipment items, and enabling the CHS to provide hypertension and diabetes services would all likely increase health service utilization at CHS level.
\end{abstract}

Key words: commune health stations, health service utilization, non-communicable diseases, service readiness, service availability 


\section{Introduction}

Rapid socioeconomic and demographic change, including rapidly rising living standards, increased technological sophistication, an aging population and an increase in the burden of noncommunicable diseases ( $\mathrm{NCD}$ ), means that the Vietnamese population has both the need and the expectation of more and better care. The hospital-centric delivery model is under strain, with hospitals suffering from overcrowding as they provide curative care services for common conditions and to patients whose health needs could be better served at the primary care level, at lower cost to the health system and greater convenience to the people. Commune health stations (CHSs) are intended to be the first point of care in the government health care system, the key primary curative care provider for the low-income population (especially in remote areas), and the main site for the delivery of preventive and promotive health programs. However, while some commune health stations (CHS) are busy and see many patients every day, others are quite underutilized. As part of the implementation of the Grassroots Masterplan, and financed by national, provincial and donor funding sources, the Government of Vietnam is planning large investment in CHS facilities, equipment and staff competencies in order to improve CHS service readiness. But, will improved service availability/readiness increase people's utilization of CHS services for common medical conditions? What domains of service readiness should be prioritized for investment and in what types of localities should investment be made to achieve the greatest increase in service utilization increases? These are some of the questions that this paper attempts to address.

Service readiness refers to the capacity of health facilities to provide health services. It can be operationalized in empirical work as the availability of the various domains of inputs, such as infrastructure, human resources, basic equipment, medicines, medical consumables, 
required to provide a specific service or sets of services [1]. Previous studies in Vietnam have focused on describing CHS service readiness, encompassing infrastructure, medical equipment, pharmaceutical products, and human resources, and find that CHSs across the country still vary significantly in their service readiness [2,3]. Empirical analysis in Vietnam has not yet sought to identify which domains of service readiness are associated with higher population utilization of commune-level primary curative care services, such analysis would be useful in guiding decisions about appropriate investments in the CHS, especially with a view to increasing utilization of needed services at this more cost-effective lower level of care, i.e. addressing both unmet need and efficiency goals.

This paper aims to quantify the variation in curative care service utilization and service readiness across CHSs in different geographical areas of Vietnam, to examine the association between different CHS service availability/readiness domains and the rate of health service utilization in their catchment communes as well as to predict CHS utilization rates for different investment scenarios.

\section{Method}

\section{Data}

The 2015 Vietnam District and Commune Health Facility Survey (DCHFS) was conducted in the same locations with the 2015 household survey to ensure the linkage in analyzing the relationship between the health seeking behavior and the quality of local provider [4]. It includes five modules: (i) facility questionnaire; (ii) health worker interviews; (iii) patient exit interviews (iv) clinical vignettes; and (v) clinical observation. The development of the instrument was informed by the questionnaires used in the Service Delivery Indicators (SDI) 
project [5], WHO's Service Availability and Readiness Assessment (SARA) [6] and the 20012002 Vietnam National Health Survey [7]. Sample design consisted of multi-stage stratified random sampling. In the first stage, six provinces, representing the six geographic regions of Vietnam, were purposively selected, with the aim of ensuring the selected province had provincial per capita income and poverty rate typical of the region. The development of the questionnaire, its scope, sampling methodology, and construction of indicators is described in more detail elsewhere [3]. The sample of the health facility survey were all commune health stations locating in the communes that were corresponding with the selected enumeration areas in the household survey. The total number of CHS included in this analysis was 246 CHSs (i.e., a representative sample of CHS in 6 selected provinces)

\section{Measurement}

The dependent variable, CHS utilization rate, is measured as the average number of primary curative care visits to the CHS per capita. It is calculated as the number of reported curative care visits to the CHS in the year preceding the DCHFS 2015, based on information collected from the CHS's records during the survey (numerator) divided by the total (estimated) commune population in 2014.

Based on the Service Delivery Indicators (SDI) project [5], the WHO's Service Availability and Readiness Assessment (SARA) [6] and the National commune Health Ben benchmarks (Ministry of Health Decision 4667), we had developed the following proxy for CHS service availability and readiness.

1. Availability of infrastructure is measured as a binary variable capturing whether the CHS meets government benchmarks (standards) for both building area and the number of 
rooms for patient care and facility administration (as defined in the Ministry of Health's Decision 4667). Specifically, CHSs in Zone 1 should have at least $150 \mathrm{~m}^{2}$ of built area while CHSs in Zones 2 and 3 should have a minimum of $250 \mathrm{~m}^{2}$. CHSs in Zone 1 should have at least five rooms, Zone 2 at least seven rooms and Zone 3 at least nine rooms. ${ }^{1}$

2. Availability of basic medical equipment/instruments is measured as a binary variable capturing whether a CHS has at least $70 \%$ of the 16 pieces of equipment on which information was collected in the DSCF. ${ }^{2}$

3. Availability of basic medicines is measured as a binary variable capturing whether the CHS has at least $70 \%$ of the 30 basic medicines that were checked in the DSCF. ${ }^{3}$

4. Availability of human resources is measured as whether the CHS has a contracted/permanent medical doctor.

5. Readiness to deliver NCD services: This domain was measured using two discrete score variables, with a higher value representing a more comprehensive service readiness.

○ Readiness to deliver hypertension-related services: The score ranges from 0 to 4 and is a simple count of the number of the following service elements provided at the CHS: a) community-based hypertension screening, b) management of cases identified as being at risk of hypertension (but who may not yet have elevated

\footnotetext{
${ }^{1}$ Patient care and facility administration rooms include rooms for clinical examination, first aid, immunization, postimmunization observation, traditional medicine services, delivery/family planning services, pharmaceutical dispensing, administrative activities, IEC, etc. However, rooms such as the toilet or storage shed would not be included.

${ }^{2}$ The $70 \%$ threshold is the benchmark in Decision 4667. The list of equipment in the survey includes: adult, child and newborn weighing scales, a thermometer, stethoscope, pinard horn to hear fetal heartbeat, blood pressure cuff, oxygen tank, bulb syringe, gastric lavage instrument set, gynecology/obstetrics table, mucus suction machine, instrument sterilization equipment, refrigerator, cold chain box, and microscope.

${ }^{3}$ The $70 \%$ threshold is the benchmark in Decision 4667. The list of drugs in the survey includes: antibiotics (7), hypertensive drugs (6), diabetes drugs (4), NSAIDS and pain meds (4), cholesterol control (2), sedative/antidepressant/epilepsy (3), diarrhea or parasite (2), acid reflux (1), and asthma/COPD (1).
} 
blood pressure), c) management and monitoring of treatment for confirmed hypertension cases, and c) regular medicine dispensing to hypertensive patients.

- Readiness to deliver diabetes-related services: The score ranges from 0 to 4 , and is a simple count of the number of the following service elements provided at the CHS: a) community-based screening, b) management of cases identified as being at risk of diabetes (but who may not yet have elevated blood glucose levels), c) management and monitoring of treatment for confirmed diabetes cases, and d) regular medicine dispensing to diabetic patients.

Remoteness is an important environmental factor that can influence CHS utilization due to proximity and lack of alternative sources of care. This factor is proxied by a categorical variable, with CHS classified into Zone 1, 2 or 3 (based on the zone definitions in the Ministry of Health's Decision 4667) [8], where level of remoteness increases with zone number. ${ }^{4}$ We created this categorical variable using three variables in the DSCF data which corresponded to definitions of zones in Decision 4667, namely a) distance from the CHS to a district hospital, b) province name, c) geographical area (rural/urban).

\section{Statistical approach}

The dependent variable - CHS utilization rate - can be assumed to follow a Poisson distribution; it expresses the probability of a given number of events occurring in a fixed interval of time or for a given population. However, the actual distribution exhibited over-dispersion (i.e.,

\footnotetext{
${ }^{4}$ Ministry of Health Decision 4667 categorizes facilities into three zones, largely based on geography and distance as follows: Zone 1 for urban locations, or rural delta and midland communes with the distance between the CHS and higher-level care less than $3 \mathrm{~km}$; Zone 2 for communes in mountainous, remote, isolated, border and maritime areas with distance between the CHS and higher-level care less than $5 \mathrm{~km}$ and delta and midland communes with distance between the CHS and higher-level care from $3 \mathrm{~km}$ to below $15 \mathrm{~km}$; Zone 3 for communes in remote areas with distance between the CHS and higher-level care of 5 or more kilometers or delta and midland communes with distance between the CHS and higher-level care of 15 or more km.
} 
the presence of greater variability in a data set than would be expected based on a given statistical model). If a Poisson regression were used in such a situation, the standard errors would be underestimated, and we might conclude that a variable has a significant effect when it doesn't. Consequently, we use a Poisson mixture model, specifically the negative binomial model.

Five progressively more complex models were used to examine the association between indicators of service readiness and CHS utilization. In model 1, the effect of health infrastructure was tested. In subsequent models, the availability of equipment (model 2), availability of medicines (model 3), availability of human resources (model 4), and readiness to delivery hypertension and diabetes services (model 5) were incrementally added. In all models, the remoteness of CHSs (measuring by CHS zone) was included as an important confounder.

\section{Results}

\section{Geographic variation in health service utilization}

The more remote the geographic zone, the higher the CHS utilization rate. Results indicate significant differences in CHS utilization rates between zone 3 (most remote rural areas) and zone 1 (urban), and between zone 2 (rural, less remote) and zone 1. However, the difference in CHS utilization rates between zones 2 and 3 is not significant. The overall CHS utilization rate was 0.62 visits per capita per year. The rate was highest in the most remote zone 3 (mean: 1.04; 95\% CI $[0.80,1.29]$ ), compared with zone 2 (mean: $0.83 ; 95 \%$ CI $[0.69,0.97]$ ) and zone 1 (mean: $0.39 ; 95 \%$ CI $[0.32,0.46]$ ) (see Table 1). Median values follow the same pattern. The mean number of CHS visits varied significantly not only across the three zones but also within each zone as can be seen by the relatively high coefficient of variation particularly in Zone 1 and Zone 3. 


\section{Table 1 about here}

\section{CHS service availability and readiness}

CHS input availability for service provision varies across geographic zones. Overall survey results indicate that $73.6 \%$ of $\mathrm{CHSs}$ satisfied government regulations with respect to infrastructure requirements. However, only $51.2 \%$ of CHS in the (remote) Zone 3 meet these standards. Some $91.5 \%$ of commune facilities had at least $70 \%$ of surveyed equipment in place, but only $17.1 \%$ of facilities had all required equipment in place. An extremely small share of CHS (2.8\%) had 70\% or more of surveyed medicines in stock. Only a little over half (57.7\%) of CHSs had a medical doctor present (Table 2).

Readiness to deliver NCD services is quite limited at the CHS. More than a quarter of CHS do not provide even the most basic level of screening for hypertension (28.5\%) and diabetes $(29.7 \%)$. The proportion of CHSs providing complete management of hypertension and diabetes (including screening, monitoring of people with risk factors, management and monitoring of treatment, and dispensing of medicines) reached only $9.8 \%$ and $24.4 \%$ respectively.

\section{Table 2 about here}

\section{Relationship between CHS service readiness and CHS health service utilization}

Table 3 present the results of the five incremental models examining the relationship between CHS service readiness and CHS utilization rates. The coefficients and level of significance of each variable are relatively stable across models as additional domains of service readiness are introduced. In all models, the remoteness of the CHS was a significant confounding variable affecting overall level of CHS utilization rates. CHSs in Zone 2 and Zone 3 had 
significantly higher utilization rates compared to the reference category of Zone 1 . In the final model, CHSs in Zone 3 had 2.9 times as many visits per capita than those in Zone 1, whereas CHSs in Zone 2 had 2.2 times as many visits per capita as those in Zone 1. Of the five domains of service readiness examined in the models, four variables in three domains were significantly associated with increased CHS utilization rates. These were CHS infrastructure meeting national standards, availability of equipment, readiness to deliver hypertension-related services and readiness to deliver diabetes-related services. The other two variables examined, namely presence of a medical doctor and availability of medicines, were not significantly associated with CHS service utilization.

In the final model (Model 5), visits per capita were 1.36 times as high when the CHS met the government's infrastructure standards, and 1.80 times as high when equipment availability met the $70 \%$ threshold than when it did not. Beyond infrastructure and equipment, readiness to deliver NCD services is also positively associated with CHS utilization. Total CHS visits per capita is 1.15 times as high for each additional service element provided in the hypertension package and 1.11 times as high for each additional service element provided in the diabetes package.

Table 3 about here

\section{Predicted CHS utilization rates for different investment scenarios}

Five variables were significantly associated with higher CHS utilization rates. Of these, four can be modified through investment (by government or donor-funded projects or communities) to improve CHS readiness, whereas the geographic zone where the CHS is located cannot be changed. This section quantifies the predicted CHS utilization rates that could be achieved through investments in improving service readiness. 
The first scenario is the hypothetical worst-case scenario, where all values are set to the worst level. In this scenario, the average number of CHS visits per capita would reach only 0.1 in Zone 1 and 0.28 in Zone 3. The second scenario is the baseline scenario, where all CHS values are set to the average of that CHS's zone. In this scenario, the predicted utilization rate would be 0.17 in Zone 1 , rising to 0.55 in Zone 3 . The third scenario predicts what would happen if investments were made to bring the infrastructure and equipment in each facility to the benchmark level (i.e. building area and number of rooms meet government standards and at least $70 \%$ of surveyed equipment is available), holding readiness to deliver NCD services at zonal averages. This scenario doubles the CHS utilization rates compared to what would be obtained with current average levels of service readiness in each zone. The utilization rate would increase to 0.36 in Zone 1, 0.85 in Zone 2, and 1.1 in Zone 3. The fourth scenario predicts what would happen if investments are sufficient to ensure not only infrastructure and equipment availability, but also that CHSs can provide all four service elements for both hypertension and diabetes. Compared to the baseline (zonal average) scenario, CHS utilization rates would increase by a factor of 3.6 in Zone 1 (to 0.62 ), by a factor of 3.7 in Zone 2 (to 1.39) and by a factor of 3.3 in Zone 3 (to 1.8). Compared to the worst case scenario, where all CHS have insufficient infrastructure and equipment, and lack capacity to deliver any NCD service, the utilization rate in communes where infrastructure is sufficient, equipment is available, and the CHS is fully able to manage hypertension and diabetes is more than 6 times as high in all zones (6.2 as high in Zone 1, 6.6 as high in Zone 2 and 6.4 times as high in Zone 3).

\section{Table 4 about here}




\section{Discussion}

This study exploited secondary data from the 2015 Vietnam DCHFS to examine the rates of primary curative care service use at CHSs in different geographic zones and the relationship between various domains of CHS service availability/readiness and service use. The findings are important for informing the design and location of investments in the CHS, but also, more generally, for strengthening primary health care in Vietnam. Results show that CHS service utilization varies significantly across geographic zones. Whereas the average number of CHS visits per capita in 2014 was only 0.39 visits for CHSs in more urban settings (Zone 1), for CHSs in remote rural areas (Zone 3) this figure was 1.04. The difference in patient load across CHSs in different geographical areas can be explained by the fact that in remote areas it is typically very difficult (e.g. in mountainous areas) or very far for patients to travel to the district hospital and there are also fewer private services are available. This means that CHSs are more likely to be used as the first, or even only, point of contact with the health care system. By contrast in zone 1 (typically urban areas where CHSs are very close to the district hospital), patients can easily bypass CHSs to go directly to district hospitals or, alternatively, use private health care services. From a health system's perspective, this bypassing behavior is costly. Moreover, since hospitals and private services focus mainly on curative care it means that people who bypass the CHS level also potentially miss out on the promotive and preventive services (including opportunistic screening) that they can obtain at the CHS.

When simultaneously examining five domains of service availability/readiness in the final model, we find that three domains of service availability/readiness have a significant association with CHS health services utilization. Those were: sufficiency of health infrastructure, availability of basic equipment, and ability to deliver services related to NCDs. CHSs whose 
building area and number of rooms for patient and facility administration met the benchmark requirement in the Ministry of Health's Decision 4667 had utilization rates 1.4 times as high as rates in those that did not meet these benchmarks $(R R=1.36)$. Interpretation of this finding requires some caution due to data being limited to a cross-section of CHSs at one point in time, making it impossible to rule out potential temporal bias or reverse causality. Our interpretation is that the larger building area and number of rooms of the CHSs that meet the benchmarks make them better able to provide services and, therefore, more attractive to patients, resulting in higher utilization rates., However, it is also possible that CHSs with higher patient loads receive more resources, or their staff have more motivation, to upgrade their building area to meet the benchmark requirement. The data are inadequate for us to determine the direction of causality.

The importance of having adequate equipment and instruments to provide quality health care services has been emphasized in the literature [9]. In fact, all the conceptual frameworks for health care delivery that were reviewed in the preparation of this manuscript include adequate equipment and medicines as key determinants of service utilization [10-12]. The results of this study support the theory: CHSs which have at least $70 \%$ of surveyed equipment have rates of services utilization that are 1.80 times as high as CHSs which have less than $70 \%$ of the equipment. One limitation is that the DCHFS collected information on only 16 equipment items. While the survey team considered these items to be representative of those items that the CHS are required to have to provide basic services, the complete list of equipment recommended by the $\mathrm{MOH}$ is much longer. ${ }^{5}$ However, since most CHS primary curative care services rely primarily on basic clinical exams for which limited equipment is required, it is reasonable to think that even this more limited equipment list could be important in terms of a visible signal of

\footnotetext{
${ }^{5} \mathrm{MOH}$ Decision 1020/2004/QĐ-BYT issuing CHS design standards.
} 
adequacy of service quality and, thus, an important determinant in deciding whether and where to seek care. While the disease burden in Vietnam has shifted such that, in 2017, NCDs account for $79 \%$ of total deaths and $74 \%$ of the disease burden [13], the health system is not yet able to provide a comprehensive package of NCD services, including both curative and preventive care. We find a significant association between the readiness to deliver NCD services and CHS utilization; the more elements of the hypertension and diabetes service packages provided by CHS, the higher the intensity of service use. This finding is important because it shows that if the CHS could provide a comprehensive set of NCD services, the number of visits to the CHS is likely to increase. The higher utilization rates could result from a more comprehensive scope of services being interpreted by people as a signal of overall service quality (and, would, therefore make the CHS more attractive to people regardless of the type of care that they were seeking). It could also result from the fact that these types of diseases, if managed properly, require monthly visits to a healthcare provider. From a health system's perspective, if CHSs were able to play a stronger role in providing outpatient services for NCDs, they would also reduce the burden of NCD management at the higher, less convenient and more expensive levels of care.

This secondary data analysis enabled us to examine a broad range of CHS characteristics in the model. Results highlighted some significant associations between modifiable CHS characteristics and service utilization, which suggest that investments in CHS infrastructure, CHS equipment, and the capacity of CHSs to deliver NCD management services (specifically hypertension and diabetes) would likely increase patient utilization at this level of the health care system. However, all the results should be interpreted taking into consideration the limitations, including the sample size and representativeness, possible measurement issues, and crosssectional nature of the data. For instance, while only three domains of service readiness were 
found to be significantly associated with CHS utilization, it does not necessarily follow that the other domains that are not significantly associated with CHS utilization are not important areas for future policy intervention. Rather, the lack of a statistically significant association could stem from insufficient statistical power to detect an effect with a sample size of $246 \mathrm{CHS}$, or that the variables used may be inadequate proxies for the concepts that they are supposed to measure. The selection of only six provinces in the original study may be insufficient to ensure the generalizability of the findings to all provinces in Vietnam.

\section{Implications for healthcare management practice}

Investments in improving facility infrastructure (especially ensuring that facilities have the mandated number of rooms and building area), making available essential equipment items, and enabling the CHS to provide hypertension and diabetes services, whether made independently or together, would all likely increase CHS utilization. Investment in CHSs in Zone 3 and Zone 2 should be prioritized over investments in Zone 1 since investments in the former would result in the highest utilization rates.

Previous studies have shown that the client's perceptions of quality in healthcare consists of 4 main dimensions, including medical staff, appropriate facilities, responsive features, and assurance [14]. The focus of this study was on service readiness, which captures the dimensions of appropriate facility and some aspects of responsive features, such as NCD services. The findings had emphasized the importance of providing a comprehensive of NCD services, from NCD prevention, NCD treatment, to NCD control at CHSs because people with NCDs would require long term care that proactive, available, accessible within their commune. 
Future studies on this topic would benefit from a larger sample size, theoretically suitable measures of CHS characteristics, and comprehensive control for other dimensions of quality in health care in order to better identify concrete priorities for future investment.

\section{References}

1. O’Neill K, Takane M, Sheffel A, Abou-Zahr C, Boerma T. Monitoring service delivery for universal health coverage: the Service Availability and Readiness Assessment. Bull World Health Organ. 2013;91:923-931.

2. Van Huy N, Nam Y-S, Van Thanh N, Tuan NT, Ha NTT, Hoat LN, et al. WHO's Service Availability and Readiness Assessment of primary health care services of commune health centers in a rural district of Northern Vietnam. Int J Health Plann Manage. 2018;33(1):202211.

3. The World Bank, Health Strategy and Policy Institute. Quality and Equity in Basic Health Care Services in Vietnam: Findings from the 2015 Vietnam District and Commune Health Facility Survey. Hanoi: The World Bank; 2016 Jun. Report No.: AUS13083.

4. The World Bank. Vietnam - District and Commune Health Facility Survey 2015 [Internet]. Central Microdata Catalogue. 2016 [cited 2019 Feb 16]. Available from: http://microdata.worldbank.org/index.php/catalog/2728/related_materials

5. The World Bank. Service Delivery Indicators [Internet]. 2017 [cited 2018 Nov 4]. Available from: http://www.sdindicators.org/

6. World Health Organization. Service Availability and Readiness Assessment (SARA) [Internet]. 2015 [cited 2018 Nov 4]. Available from:

http://www.who.int/healthinfo/systems/sara_introduction/en/

7. Vietnam Ministry of Health, General Statistics Office. Vietnam National Health Survey 2001-2002. Health Facility Questionnaire. Hanoi; 2001.

8. Vietnam Ministry of Health. Decision No. 4667 issuing the national commune health benchmarks to the year 2020. Decision Nov 7, 2014.

9. Mosadeghrad AM. Factors influencing healthcare service quality. Int J Health Policy Manag. 2014;3(2):77.

10. Andersen R, Newman JF. Societal and individual determinants of medical care utilization in the United States. Milbank Mem Fund Q Health Soc. 1973;95-124. 
11. Andersen RM. Revisiting the behavioral model and access to medical care: does it matter? J Health Soc Behav. 1995;1-10.

12. World Health Organization. Everybody's business: strengthening health systems to improve health outcomes. WHO's Framework for Action. Geneva: World Health Organization; 2007.

13. Global Burden of Disease Collaborative Network. Global Burden of Disease Study 2017 (GBD 2017) Results [Internet]. Seattle, United States: Institute for Health Metrics and Evaluation (IHME); 2018. Available from: http://ghdx.healthdata.org/gbd-results-tool

14. Weheba G, Cure L, Toy S. Perceived dimensions of healthcare quality in published research. Int J Healthc Manag. 2018;1-8. 
Table 1: CHS utilization rates per year by CHS zone

\begin{tabular}{|c|c|c|c|c|}
\hline & Overall & Zone 1 & Zone 2 & Zone 3 \\
\hline Summary definition & All 3 zones & $\begin{array}{c}\text { Urban and peri- } \\
\text { rban }\end{array}$ & Rural not remote & Remote rural \\
\hline Mean & 0.62 & 0.39 & 0.83 & 1.04 \\
\hline Std. Deviation & 0.60 & 0.43 & 0.56 & 0.78 \\
\hline $95 \%$ confidence interval around the mean & {$[0.55,0.70]$} & {$[0.32,0.46]$} & {$[0.69,0.97]$} & {$[0.80,1.29]$} \\
\hline Median & 0.41 & 0.25 & 0.75 & 0.98 \\
\hline Observations & 246 & 137 & 66 & 43 \\
\hline
\end{tabular}


Table 2: CHS service availability and readiness

\begin{tabular}{|c|c|c|c|c|c|}
\hline & & \multicolumn{4}{|c|}{ Percentage of CHS } \\
\hline Domain & $\begin{array}{c}\text { Variable } \\
\text { definition/category }\end{array}$ & $\begin{array}{l}\text { Overall } \\
(n=246)\end{array}$ & $\begin{array}{l}\text { Zone 1 } \\
(\mathrm{n}=137)\end{array}$ & $\begin{array}{l}\text { Zone } 2 \\
(n=66)\end{array}$ & $\begin{array}{l}\text { Zone 3 } \\
(n=43)\end{array}$ \\
\hline & & $\%$ & $\%$ & $\%$ & $\%$ \\
\hline $\begin{array}{l}\text { Health } \\
\text { infrastructure }\end{array}$ & $\begin{array}{r}\text { Building area and number } \\
\text { of rooms meet Decision } \\
4667 \text { benchmarks }\end{array}$ & 73.6 & 78.1 & 78.8 & 51.2 \\
\hline $\begin{array}{l}\text { Basic } \\
\text { equipment/ } \\
\text { instruments }\end{array}$ & $\begin{array}{r}\text { Have at least } 70 \% \text { of } \\
\text { surveyed equipment at } \\
\text { time of survey }\end{array}$ & 91.5 & 89.8 & 95.3 & 90.7 \\
\hline Medicines & $\begin{array}{r}\text { Have at least } 70 \% \text { of } \\
\text { surveyed medicines at time } \\
\text { of survey }\end{array}$ & 2.8 & 2.2 & 4.5 & 2.3 \\
\hline $\begin{array}{l}\text { Human } \\
\text { resources }\end{array}$ & $\begin{array}{l}\text { Have a contracted or } \\
\text { permanent general doctor }\end{array}$ & 57.7 & 56.9 & 60.6 & 55.8 \\
\hline & & $\begin{array}{l}\text { Mean } \\
\text { (SD) }\end{array}$ & $\begin{array}{l}\text { Mean } \\
\text { (SD) }\end{array}$ & $\begin{array}{l}\text { Mean } \\
\text { (SD) }\end{array}$ & $\begin{array}{r}\text { Mean } \\
\text { (SD) }\end{array}$ \\
\hline $\begin{array}{r}\text { Service } \\
\text { readiness scores }\end{array}$ & $\begin{array}{r}\text { Hypertension service } \\
\text { availability }\end{array}$ & $\begin{array}{c}1.99 \\
(1.57)\end{array}$ & $\begin{array}{c}1.86 \\
(1.61)\end{array}$ & $\begin{array}{c}2.10 \\
(1.86)\end{array}$ & $\begin{array}{c}2.21 \\
(1.52)\end{array}$ \\
\hline $\begin{array}{r}\text { (ranges from } 0 \\
\text { to } 4 \text { ) }\end{array}$ & $\begin{array}{r}\text { Diabetes service } \\
\text { availability }\end{array}$ & $\begin{array}{c}1.67 \\
(1.35)\end{array}$ & $\begin{array}{l}1.61 \\
(1.35)\end{array}$ & $\begin{array}{c}1.82 \\
(1.40)\end{array}$ & $\begin{array}{c}1.65 \\
(1.25)\end{array}$ \\
\hline
\end{tabular}


Table 3: Incremental negative binomial models to measure the association between service readiness domains and CHS service utilization

\begin{tabular}{|c|c|c|c|c|c|c|c|c|c|c|c|c|c|c|c|}
\hline \multirow[b]{2}{*}{$\begin{array}{l}\text { Explanatory } \\
\text { variables }\end{array}$} & \multicolumn{3}{|c|}{ Model 1} & \multicolumn{3}{|c|}{ Model 2} & \multicolumn{3}{|c|}{ Model 3} & \multicolumn{3}{|c|}{ Model 4} & \multicolumn{3}{|c|}{ Model 5} \\
\hline & $\mathbf{R R}$ & $\begin{array}{c}95 \% \\
\text { CI }\end{array}$ & $\begin{array}{c}\text { p- } \\
\text { valu } \\
\text { e }\end{array}$ & $\mathbf{R R}$ & $\begin{array}{c}95 \% \\
\text { CI }\end{array}$ & $\begin{array}{c}\text { p- } \\
\text { valu } \\
\text { e }\end{array}$ & $\mathbf{R R}$ & $\begin{array}{c}95 \% \\
\text { CI }\end{array}$ & $\begin{array}{c}\text { p- } \\
\text { valu } \\
\text { e }\end{array}$ & $\mathbf{R R}$ & $\begin{array}{c}95 \% \\
\text { CI }\end{array}$ & $\begin{array}{c}\text { p- } \\
\text { valu } \\
\text { e }\end{array}$ & $\mathbf{R R}$ & $\begin{array}{c}95 \% \\
\text { CI }\end{array}$ & $\begin{array}{c}\text { p- } \\
\text { valu } \\
\text { e }\end{array}$ \\
\hline $\begin{array}{l}\text { CHS zone } 2 \text { vs. } \\
\text { zone } 1\end{array}$ & 2.18 & $\begin{array}{r}{[1.65} \\
2.88]\end{array}$ & 0.00 & 2.18 & $\begin{array}{r}1.66 \\
, \\
2.86]\end{array}$ & 0.00 & 2.14 & $\begin{array}{r}{[1.63} \\
28.2]\end{array}$ & 0.00 & 2.13 & $\begin{array}{r}{[1.62} \\
2.80]\end{array}$ & 0.00 & 2.22 & $\begin{array}{r}1.74 \\
, \\
2.85]\end{array}$ & 0.00 \\
\hline $\begin{array}{l}\text { CHS zone } 3 \text { vs. } \\
\text { zone } 1\end{array}$ & 3.11 & $\begin{array}{r}{[2.21} \\
4.38]\end{array}$ & 0.00 & 2.86 & $\begin{array}{r}{[2.04} \\
4.02]\end{array}$ & 0.00 & 2.85 & $\begin{array}{r}{[2.03} \\
3.99]\end{array}$ & 0.00 & 2.83 & $\begin{array}{r}{[2.02} \\
3.98]\end{array}$ & 0.00 & 2.87 & $\begin{array}{r}{[2.13} \\
, \\
3.88]\end{array}$ & 0.00 \\
\hline Infrastructure & 1.51 & $\begin{array}{r}{[1.14} \\
2.01]\end{array}$ & 0.00 & 1.39 & $\begin{array}{r}{[1.05} \\
, \\
1.84]\end{array}$ & 0.02 & 1.39 & $\begin{array}{r}{[1.05} \\
, \\
1.85]\end{array}$ & 0.02 & 1.38 & $\begin{array}{r}{[1.04} \\
1.84]\end{array}$ & 0.03 & 1.36 & $\begin{array}{r}{[1.06} \\
, \\
1.75]\end{array}$ & 0.02 \\
\hline Equipment & & & & 2.11 & $\begin{array}{r}{[1.37} \\
3.25]\end{array}$ & 0.00 & 2.07 & $\begin{array}{r}{[1.35} \\
3.18]\end{array}$ & 0.00 & 2.07 & $\begin{array}{r}{[1.34} \\
3.18]\end{array}$ & 0.00 & 1.80 & $\begin{array}{r}{[1.22} \\
, \\
2.65]\end{array}$ & 0.00 \\
\hline Medicines & & & & & & & 1.67 & $\begin{array}{r}{[0.83} \\
, \\
3.36] \\
\end{array}$ & 0.15 & 1.65 & $\begin{array}{r}{[0.82} \\
3.33] \\
\end{array}$ & 0.16 & 1.25 & $\begin{array}{r}0.66 \\
, \\
2.36]\end{array}$ & 0.50 \\
\hline Medical doctor & & & & & & & & & & 1.08 & $\begin{array}{r}{[0.85} \\
, \\
1.37]\end{array}$ & 0.53 & 1.13 & $\begin{array}{r}{[0.91} \\
, \\
1.39]\end{array}$ & 0.28 \\
\hline $\begin{array}{l}\text { Readiness to } \\
\text { deliver } \\
\text { hypertension- } \\
\text { related services }\end{array}$ & & & & & & & & & & & & & 1.15 & $\begin{array}{r}{[1.06} \\
, \\
1.24]\end{array}$ & 0.00 \\
\hline $\begin{array}{l}\text { Readiness to } \\
\text { deliver diabetes- } \\
\text { related services }\end{array}$ & & & & & & & & & & & & & 1.11 & $\begin{array}{r}{[1.01} \\
, \\
1.22]\end{array}$ & 0.02 \\
\hline
\end{tabular}


Table 4: Predicted CHS utilization rates for different hypothetical service readiness scenarios

\begin{tabular}{|c|c|c|c|}
\hline Scenario & Zone 1 & Zone 2 & Zone 3 \\
\hline $\begin{array}{l}\text { Worst cases (no CHS meeting infrastructure standard, less } \\
\text { than } 70 \% \text { of equipment and no services for hypertension } \\
\text { and diabetes) }\end{array}$ & 0.10 & 0.21 & 0.28 \\
\hline Current average levels of each variable in each zone & 0.17 & 0.38 & 0.55 \\
\hline $\begin{array}{l}\text { All CHS in zone meet infrastructure standards and have } \\
70 \% \text { of equipment on list }\end{array}$ & 0.36 & 0.85 & 1.10 \\
\hline $\begin{array}{l}\text { All CHSs in zone meet infrastructure standards, have at } \\
\text { least } 70 \% \text { of equipment on list, and offer full set of NCD } \\
\text { (hypertension and diabetes) services s }\end{array}$ & 0.62 & 1.39 & 1.80 \\
\hline
\end{tabular}


